\title{
Impact of Consumer-Driven Changes to Crop Production Practices on Lettuce Drop Caused by Sclerotinia sclerotiorum and $S$. minor
}

\author{
B. M. Wu, S. T. Koike, and K. V. Subbarao
}

First and third authors: Department of Plant Pathology, University of California at Davis, U.S Agricultural Research Station, Salinas, CA 93905; and second author University of California Cooperative Extension, Salinas 93901. Current address of B. M. Wu: Central Oregon Agricultural Research Center, Madras 97741. Accepted for publication 25 October 2010.

\begin{abstract}
Wu, B. M., Koike, S. T., and Subbarao, K. V. 2011. Impact of consumerdriven changes to crop production practices on lettuce drop caused by Sclerotinia sclerotiorum and S. minor. Phytopathology 101:340-348.

Increasing demands for value-added salad products have triggered revolutionary changes in the production practices of vegetable salad crops in recent years. One of the pivotal changes is the adaptation of 2-m-wide beds for increased vegetable biomass per unit area. The move away from the traditional 1-m-wide raised beds in cool-season vegetable production and the associated irrigation practices potentially can have a major influence on diseases affecting cool-season vegetables. To assess the potential impacts of this shift on lettuce drop caused by Sclerotinia minor and S. sclerotiorum, the two bed widths and different irrigation frequencies within each were compared in two separate field experiments over four lettuce crops in 2 years. Treatments included 1- and 2-m bed widths with twice-weekly, weekly and biweekly drip irrigation serving as subplot treatments that were begun immediately following thinning. Incidence of lettuce drop was evaluated weekly thereafter until maturity.

For S. sclerotiorum, 36 half-liter soil samples were also collected once each season and assayed for the number of sclerotia, and apothecia were counted weekly in a $10-\mathrm{m}^{2}$ area for each plot. Regardless of the species, the effects of bed width and irrigation frequency were both significant. Twice-weekly irrigation and 2-m bed width resulted in higher lettuce drop incidence than other treatments. For S. sclerotiorum, twice-weekly irrigation and 2-m bed width also significantly increased the number of apothecia per unit area and the accumulation of soilborne sclerotia over multiple cropping seasons. Results demonstrated that the 2-m bed width combined with the practiced frequency of irrigations can result in higher lettuce drop caused by $S$. minor and increased incidence of airborne infection by $S$. sclerotiorum in the Salinas Valley where, historically, it has not been a serious threat. Increased incidence of $S$. sclerotiorum infection in commercial lettuce fields in the Salinas Valley between 2001 and 2006 validates these experimental results. These relatively new crop production practices can alter the balance of the two Sclerotinia spp. that has long existed in California.
\end{abstract}

Lettuce is the most widely consumed vegetable in the United States. Annually, the United States produces $\approx 4.4$ million tons of lettuce (Food and Agriculture Organization of United Nations at http://faostat.fao.org/faostat/collections?subset=agriculture), and $\approx 95 \%$ of the U.S. production occurs in California (67 to 76\%) and Arizona (United States Department of Agriculture [USDA], the National Agricultural Statistics Service at http://www.nass.usda.gov). With a farm gate value of $\$ 1.7$ billion (USDA, the National Agricultural Statistics Service at http://www.nass.usda.gov) in 2009 , lettuce is mainly produced throughout the year in the coastal Salinas and Santa Maria Valleys, and during late fall and winter in Arizona and the San Joaquin, Imperial, and Palo Verde valleys in California (21).

Lettuce drop caused by Sclerotinia minor and S. sclerotiorum is one of the most important diseases of lettuce in the world. It has also long been the most threatening disease for lettuce production in California and Arizona; thus, its management is a high priority for growers (Pest Management Strategic Plans 2003). Despite extensive germplasm screening, very few lettuce accessions with heritable resistance to lettuce drop have been identified $(9,12)$.

Corresponding author: K. V. Subbarao; E-mail address: kvsubbarao@ucdavis.edu

* The $\boldsymbol{e}$-Xtra logo stands for "electronic extra" and indicates that Figure 3 appears in color online.

doi:10.1094/PHYTO-07-10-0182

(C) 2011 The American Phytopathological Society
Control of lettuce drop has mainly relied on the application of fungicides $(13,14)$ or site selection, where lettuce is planted in fields without a history of severe problems.

Both $S$. sclerotiorum and $S$. minor survive mainly as sclerotia in soil. For lettuce drop caused by $S$. sclerotiorum, ascospores produced through carpogenic germination of sclerotia are the primary source of inoculum, although the pathogen infects plants occasionally by myceliogenic germination of sclerotia $(1,2,17$, 25). Carpogenic germination of sclerotia in $S$. minor seldom occurs in nature, and the pathogen mainly infects plants via eruptive germination $(2,10,18,20,25)$.

Despite the long history of lettuce cultivation in California, the two species have had a unique geographic distribution. S. minor is predominant in the Salinas Valley and S. sclerotiorum in the San Joaquin Valley (31). However, the reasons behind these unique niches had remained a mystery until recently. Several factors that may contribute to this distribution were studied over many years $(31,32)$. Among these factors, differential survival of the two species in their niche valleys partially contributes to their current distribution. Only a small fraction of sclerotia of $S$. minor survive in the San Joaquin Valley 6 months after their release into the soil whereas $>90 \%$ survive in the Salinas Valley. In contrast, sclerotia of $S$. sclerotiorum survive well in both valleys after prolonged burial (32). Concurrently, the response of the two species to different levels of oxygen in combination with soil moisture and temperature was also evaluated (32). The combination of high temperature, high soil moisture, and reduced oxygen in irrigated 
fields contributed to the lower survival of both Sclerotinia spp., and the responses of the two species to these conditions shape their relative geographical distribution within California. Although this study explained why $S$. minor infections in the San Joaquin Valley lettuce fields are rare, the lack of S. sclerotiorum airborne infections in the Salinas Valley lettuce fields remained unanswered. S. sclerotiorum has been considered an insignificant threat to lettuce production in the Salinas Valley because the pathogen is believed unable to produce adequate apothecia and airborne ascospores to infect lettuce during the irrigated cropping seasons. S. sclerotiorum requires $\approx 35$ days of continuous soil moisture at field capacity in the top soil (in the upper 5 to $7.5 \mathrm{~cm}$ of the soil profile) to produce apothecia (31). These conditions are routinely met during winter lettuce production periods in the San Joaquin Valley (because it coincides with the onset of rain in California) but are seldom met during the irrigated lettuce production in the Salinas Valley. These conditions are also met in the Salinas Valley during the rainy season from December to February; however, there is either little lettuce in commercial fields (because of the mandated "lettuce-free" period) or, when present, it is at growth stages unsuitable for infection. Thus, even though ascospores are abundant during December to February, lack of lettuce crops at stages conducive to infection renders these ascospores ineffective (31). Furthermore, any prolonged ( $>10$ days) dry period resets the clock for carpogenic germination and, thus, ascospore infections in lettuce in coastal California rarely occur during irrigated spring and summer lettuce production (31).

In recent years, the popularity of ready-to-eat salad mixes and a desire to achieve greater efficiency in lettuce production have led to the adaptation of a new, wider bed configuration with greater plant density. Because the size of the lettuce head is not a major issue for salad mixes, increasing plant density offers an ideal opportunity to maximize lettuce production per unit area. Thus, the $2-\mathrm{m}$ bed configuration, with 5 to 6 rows of lettuce or 16 to 20 rows of mixed leafy green species (baby leaf lettuces, endive, arugula, and others) on each bed, is taking hold as a standard production practice for salad mixes. Usually, two to three surface drip lines per bed are used to irrigate the five to six lettuce rows under this production practice. Although this offers the desired benefit of producing more lettuce or salad mix volume per unit area, it is also likely to lead to some unintended disease consequences. First, compared with the standard 1-m bed configuration, irrigation under the $2-\mathrm{m}$ bed configuration is likely to increase the soil moisture in the upper soil profiles. Second, the higher plant density on 2-m beds is likely to result in greater moisture retention under the plant canopies. These changes theoretically can lead to increased incidence of lettuce drop caused mainly by $S$. minor (10). Carpogenic germination of $S$. sclerotiorum occurs under uninterrupted soil moisture between -0.3 and $-0.01 \mathrm{MPa}$ and temperatures between 15 and $25^{\circ} \mathrm{C}$, with $-0.01 \mathrm{MPa}$ and $18^{\circ} \mathrm{C}$ being the optimum soil moisture and temperature, respectively (31). Soil temperature in the Salinas Valley is optimal for production of apothecia by S. sclerotiorum during most of the year. Thus, the changes in vegetable production that have occurred over the past decade may provide optimal soil moisture conditions for apothecium production and, therefore, lead to the increase of airborne inoculum of $S$. sclerotiorum in commercial fields in the Salinas Valley. Because millions of ascospores can be produced from each apothecium (22), the risk posed by lettuce drop caused by airborne ascospores of $S$. sclerotiorum is significantly greater and harder to control than that caused by soilborne sclerotia of $S$. sclerotiorum.

The objectives of this study were to evaluate the effects of bed width and irrigation frequency on epidemics of lettuce drop caused by $S$. minor and $S$. sclerotiorum and to assess the potential of $S$. sclerotiorum to infect lettuce via airborne ascospores; and to determine the long-term risk of $S$. sclerotiorum to become a threat to lettuce as a result of the agronomic changes in lettuce production in the Salinas Valley.

\section{MATERIALS AND METHODS}

Effects of bed width and irrigation on lettuce drop caused by $S$. minor and $S$. sclerotiorum. The effects of bed widths and irrigation frequency on lettuce drop caused by $S$. sclerotiorum and $S$. minor were studied in field experiments at two separate sites (USDA Agricultural Research Station and Hartnell College East Campus, Salinas, CA) from the spring 2004 to fall 2005 seasons. The USDA site was treated with $67 \%$ methyl bromide and $33 \%$ chloropicrin at $361 \mathrm{~kg} / \mathrm{ha}$ to eliminate any residual inoculum of $S$. minor from prior experiments. Except for the differences in the species of Sclerotinia at the two sites, treatments were identical and included two bed widths ( 1 and 2 m) and three irrigation frequencies (twice-weekly, weekly, and biweekly) with three replications. The plots were arranged in a split-plot design with bed width as the main factor and irrigation frequency as the subplot factor. Each plot consisted of $210 \mathrm{~m}^{2}$ (15-m length of 7 2-m-wide beds, each with five rows of lettuce plants, or 14 1-m-wide beds, each with two rows of lettuce plants) for the USDA site with $S$. sclerotiorum, and 60 or $90 \mathrm{~m}^{2}(15-\mathrm{m}$ length of three 2-m-wide beds or four 1-m-wide beds) for the Hartnell site with $S$. minor. The location of each plot was fixed for the entire experiment duration over four growing seasons, and the integrity of the plots was ensured by only allowing tillage operations in the same north-south direction as the plant beds were oriented.

The fields at both sites were infested once at the beginning of the first lettuce crop to ensure uniform distribution of the inoculum across all treatments. Sclerotia of multiple isolates of each species collected from coastal California lettuce fields were reproduced in the laboratory (14), air dried at room temperature, mixed, and planted along the seed lines (all lines for $S$. minor and every other line for $S$. sclerotiorum) at a $1.27-\mathrm{cm}$ depth using an EarthWay Precision Seeder (EarthWay Products, Inc., Bristol, IN). Sclerotia were planted at $69 \mathrm{~m}^{-1}$ of seed line (or 8,328 sclerotia/plot) for $S$. slcerotiorum and 1,500 sclerotia $\mathrm{m}^{-1}$ (or 181,044 sclerotia/plot) for $S$. minor. Crisphead lettuce cv. Salinas was grown during spring and fall 2004 and 2005. For each crop, sprinkler irrigation was first used for all plots to promote uniform emergence of lettuce seedlings. Three weeks after emergence, when the majority of lettuce seedlings were at the three- to fourtrue-leaf growth stage (24), seedlings were thinned to a spacing of $30 \mathrm{~cm}$. Drip irrigation was then deployed and different irrigation treatments begun immediately after thinning. The drip tapes with the same irrigation schedule were connected to the same main supply line and a flow meter was installed for each main line. The plots with twice-weekly irrigation were watered on Tuesday and Friday of each week, the plots with weekly irrigation were watered on Friday of each week, and the plots with biweekly irrigation were watered every other Friday. During each irrigation event, the plots were watered at constant pressure for approximately the same length of time. The amount of water received at each irrigation event was recorded for each main line $(14.1 \pm$ $2.7 \mathrm{~mm}$ for the $S$. sclerotiorum site and $18.6 \pm 1.7 \mathrm{~mm}$ for the $S$. minor site). Total numbers of lettuce plants on the central 5 2-m beds or $101-\mathrm{m}$ beds in each plot at the S. sclerotiorum site and on $32-\mathrm{m}$ beds or $41-\mathrm{m}$ beds at the $S$. minor site were determined after thinning. Within the same areas, the plants exhibiting drop symptoms were counted weekly for calculating disease incidence and continued until harvest maturity. In addition to drop incidence, at the site with $S$. sclerotiorum, the number of apothecia in a $10-\mathrm{m}^{2}$ area was counted weekly in each plot after the first appearance of apothecia until a week prior to harvest. In total, three or four weekly observations were made each season 
from spring 2004 to fall 2005. Ascospore release was also monitored weekly by exposing three plates of a medium semiselective for S. sclerotiorum (23) on the beds from 12:00 noon to 1:00 p.m. After exposure for $1 \mathrm{~h}$, the plates were covered and incubated in the laboratory at $20^{\circ} \mathrm{C}$ for $72 \mathrm{~h}$. The numbers of S. sclerotiorum colonies on each plate were then counted. Starting from the second lettuce crop (fall 2004), the density of soilborne sclerotia of $S$. sclerotiorum was determined before thinning of each crop. An area $6 \mathrm{~m}$ long and $6 \mathrm{~m}$ wide (three 2-m beds or six 1-m beds) was demarcated in the center of each plot. Within this area, grids of $36(6 \times 6)$ contiguous quadrats $\left(1 \times 1 \mathrm{~m}^{2}\right)$ were demarcated. A 1-liter soil sample was collected from the top $5 \mathrm{~cm}$ of soil in each quadrat, and the numbers of sclerotia in 0.5 liter of soil were determined for each sample by wet sieving (26).

Data analysis. Final lettuce drop incidence for both sites was calculated according to the total plants and plants infected at harvest, and the area under the disease progress curve (AUDPC) for each plot was calculated according to the weekly disease evaluation for each species and treatment. Data were fitted to a mixed model to test the fixed effects using Procedure Mixed in SAS (version 9.2; SAS Institute Inc., Cary, NC) on AUDPC data and arcsine-transformed final incidence. Block and interactions between block and other factors were considered as random effects. Bed width, irrigation, season, year, and their interactions were considered fixed effects.

Similar analysis was also performed to test the (fixed) effects of bed width and irrigation frequency on the number of apothecia produced by $S$. sclerotiorum per square meter using Procedure Mixed in SAS. Block and its interactions with other factors were considered random effects while bed width, irrigation frequency, crop (two crops each in 2004 and 2005), and their interactions were considered fixed effects.

Analysis using Procedure Mixed in SAS was also performed on the number of sclerotia. Upon finding significant interaction of bed width and irrigation frequencies but insignificant effects of bed width itself, the whole data set was divided into three subsets according to the irrigation frequency. The effects of bed width were then tested by performing analysis of variance on each of the subdata sets.

Field survey. To confirm our findings in commercial production systems, lettuce fields in the Salinas Valley with lettuce at late growth stages ( $>16$ leaves for Romaine lettuce and at mature heads for head lettuce) were randomly surveyed in spring 2000 (30), 2005, and 2006. In each field, 100 to 2,000 (varying with drop incidence on lettuce) plants were examined for lettuce drop and the field was classified according to presence or absence of infection by $S$. sclerotiorum, which was identified based on the presence of sclerotia of $S$. sclerotiorum on the exposed surface of the heads in the field and confirmed in laboratory culture. In total, 132, 72, and 48 fields were surveyed in 2000, 2005, and 2006, respectively. Because consistently more fields with infection by $S$. sclerotiorum were observed in the southern part than in the northern part of the Salinas Valley, as reported previously (30), the Valley was divided into two halves from the median point of the 48 fields (latitude $=36.41^{\circ} \mathrm{N}$ ) so that there were 24 fields in each part of the Valley, and the Valley was divided from the same place for surveys in 2000 and 2005. The percentage of fields in which $S$. sclerotiorum infection was observed was calculated for both northern and southern parts of the valley in each and compared among years.

Release and dispersal of $S$. sclerotiorum ascospores. Apothecia of $S$. sclerotiorum were produced in foam cups as described previously (31). When $>50 \%$ of the apothecia in cups were mature (fully expanded), the bottom halves of the cups were excised and the upper halves of cups with apothecia were buried in a microplot ( 1 by $1 \mathrm{~m}$ ) at the Salinas USDA station, such that the top of each cup was $2 \mathrm{~cm}$ above the soil surface. The microplot was irrigated daily and the circadian rhythm of ascospore release was monitored 3 days later. Petri dishes with the medium semiselective for $S$. sclerotiorum (24) were placed upside-down on two 1-mm-diameter steel sticks above the cup every $2 \mathrm{~h}$ within a $24-\mathrm{h}$ period. After exposure for $15 \mathrm{~min}$, the plates were covered and incubated in the laboratory at $20^{\circ} \mathrm{C}$ for $72 \mathrm{~h}$. The numbers of S. sclerotiorum colonies on each plate were then counted. Because accuracy in counting individual colonies could not be ensured when the number of colonies exceeded 200, an asymptote of 200 colonies was assigned to such plates. This experiment was conducted on three different days with three to five plates placed over each cup at each 2-h interval during a 24-h period.

To determine the dispersal gradient of ascospores, sclerotia of $S$. sclerotiorum were buried in a 0.3 -m-diameter circle area in a microplot $(1$ by $1 \mathrm{~m}$ ) located at the USDA Salinas station. The microplot was irrigated daily to promote carpogenic germination of sclerotia. When apothecia were fully developed (after nearly 40 days of burial), plates with semiselective medium for S. sclerotiorum were placed at $0,1,3,7$, and $11 \mathrm{~m}$ from the center of the inoculum source along both upwind and downwind directions. After a 1-h exposure from 12:00 to 1:00 p.m. (determined to be the maximum ascospore release period from the previous experiment), the plates were covered and incubated in the laboratory at room temperature for 3 days and then colonies on the plates were counted. This was repeated five times.

Analysis of variance was performed on the ascospore release data to test the time effects on the numbers of $S$. sclerotiorum colonies per plate using a general linear model in SAS (release 9.2; SAS Institute Inc.). Upon finding significant time effects, a sine function, $y=a+b \times \sin \left[2 \pi(t / 24)^{\mathrm{c}}+d\right]$, was fitted to the pattern of released ascospores $(y)$ over time ( $t$, in hours) during the day using a nonlinear regression model in SAS.

\section{RESULTS}

Effects of bed width and irrigation on lettuce drop caused by $S$. minor. Because lettuce drop incidence caused by $S$. minor in 2005 followed patterns similar to 2004, only 2004 results are presented (Fig. 1). Incidence caused by $S$. minor increased incrementally through lettuce maturity, revealing that plant-to-plant spread is limited, especially when incidence is relatively low (Fig. 1). Lettuce drop incidence caused by $S$. minor showed significant seasonal effects, with the disease generally higher in the fall than in the spring (Fig. 1; Table 1). Although overall difference between the 2 years was not significant, the interaction of yearseason was significant (Table 1), likely because of the delayed planting of the fall 2005 crop and the resultant lower disease incidence relative to the fall 2004 crop (data not shown). Drop incidence was significantly higher in plots with twice-a-week irrigation than in plots with other irrigation frequencies (Fig. 1) and exhibited significant effects of irrigation frequency (Table 1). Lettuce drop incidence caused by S. minor was higher in plots of 2-m bed width than in plots of 1-m bed width (Fig. 1), and the effects of bed width were significant (Table 1). The interaction of irrigation frequency-bed width was also significant (Table 1) in that the difference among irrigation frequency treatments varied with bed width; differences were generally greater on 2-m beds than on 1-m beds. Because the results obtained from AUDPC of drop caused by $S$. minor were similar to those from final disease incidence, results for these data are not shown. Despite extensive examinations, no apothecia of $S$. minor were observed in any plot during the study.

Effects of bed width and irrigation on lettuce drop caused by $S$. sclerotiorum. For all crops, drop incidence caused by $S$. sclerotiorum remained low $(<2 \%)$ until 2 weeks before the end of the crop season but increased quickly within the last 2 weeks in plots with twice-weekly irrigation (Fig. 2). Almost $100 \%$ of infections by $S$ sclerotiorum were caused by airborne spores. An infection can be classified as aerial infection when the lesions are 
initiated from top of the lettuce head or leaf parts that were not in contact with the soil (Fig. 3). At the end of each crop season, drop incidence caused by $S$. sclerotiorum was significantly higher in plots with twice-weekly irrigation than in plots with other irrigation frequencies (Fig. 2). In three of four crops, the average final drop incidence in plots with twice-weekly drip irrigation was $42.6 \%$ or higher whereas the average was only $6.4 \%$ for fall 2005 , when lettuce was planted at a later date and harvested before the disease developed further (data not shown). Bed width, irrigation frequency, and their interactions significantly affected lettuce drop caused by $S$. sclerotiorum (Table 2). Once again, the results from the analysis of AUDPC data for lettuce drop caused by $S$. sclerotiorum were also similar to the results obtained with final disease incidence (data not shown). Total amount of water received for plots with different irrigation frequencies is summarized for each season in Table 3.

The number of apothecia per square-meter area produced by $S$. sclerotiorum exhibited trends similar to those of drop incidence (Fig. 4). Significantly more apothecia were produced in plots with twice-weekly drip irrigation than with other irrigation frequencies and more on $2-\mathrm{m}$ bed configuration than on 1-m bed configuration at this frequency (Fig. 4). Bed width, irrigation frequency, and their interactions significantly affected the number of apothecia per square-meter area (Table 4). Production of apothecia also showed significant variation among years and seasons and significant interaction of irrigation-year (Table 4). The number of
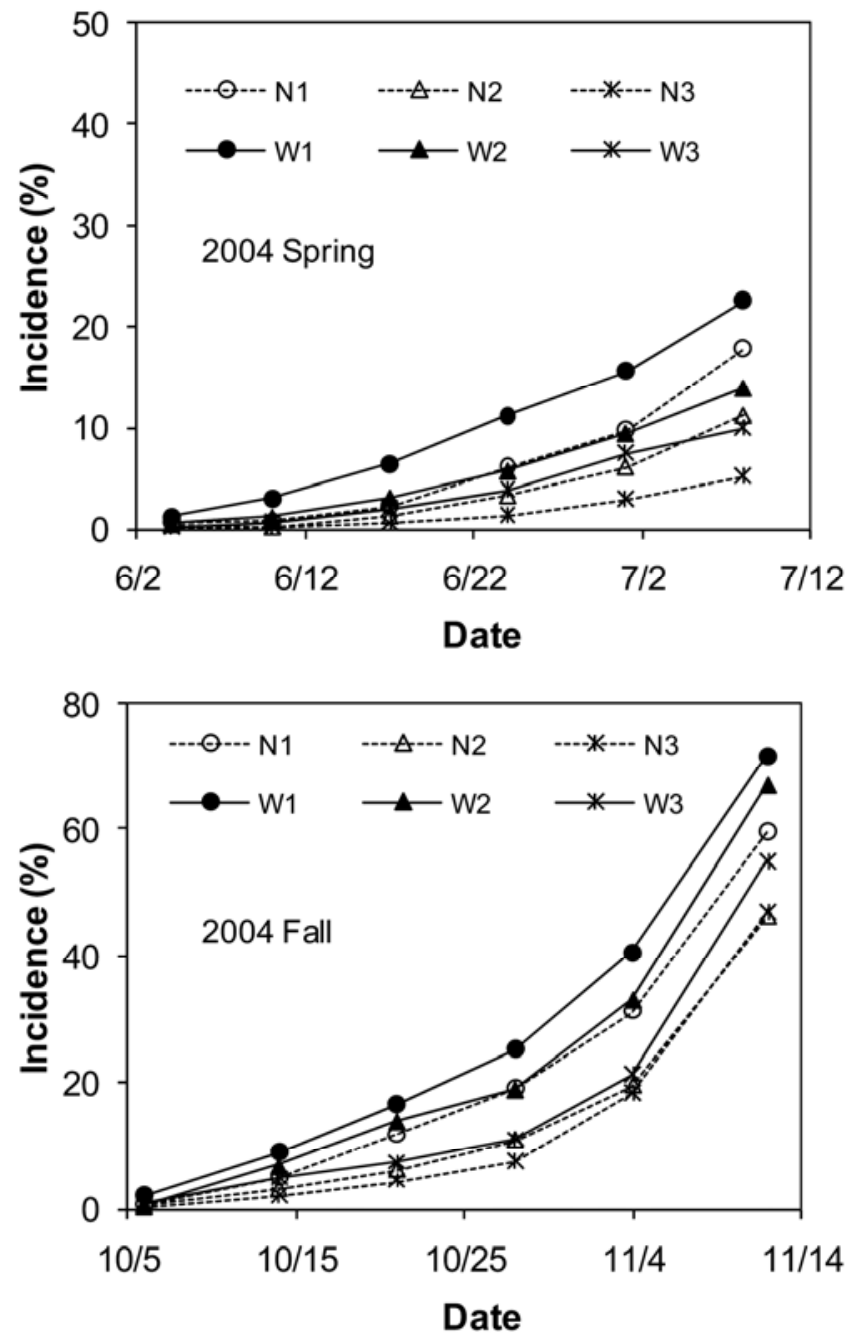

Fig. 1. Progress curves of lettuce drop caused by Sclerotinia minor during spring and fall 2004. N1, N2, and N3 denote plots of 1-m-wide beds while W1, W2, and W3 denote 2-m-wide beds with twice-weekly, weekly, and biweekly irrigation frequencies, respectively. ascospores deposited on plates also followed similar trends but was less discernible among treatments (data not shown).

In plots with twice-weekly irrigation, the density of $S$. sclerotiorum sclerotia in the top soil (0 to $5 \mathrm{~cm}$ of depth) increased over cropping seasons during the study, and the increase was greater in plots with 2-m-wide beds than in plots with 1-m-wide beds (Fig.

TABLE 1. Type III tests of fixed effects from the mixed-model analysis of the final lettuce drop incidence caused by Sclerotinia minor

\begin{tabular}{lccrr}
\hline Effect & Num & Den & & \\
DF & DF & $F$ value & \multicolumn{1}{c}{$P>F$} \\
\hline Irrigation & 2 & 32 & 15.31 & $<0.0001$ \\
Bed & 1 & 12 & 21.31 & 0.0006 \\
Irrigation $\times$ bed & 2 & 32 & 4.22 & 0.0237 \\
Season & 1 & 12 & 61.07 & $<0.0001$ \\
Irrigation $\times$ season & 2 & 32 & 7.47 & 0.0022 \\
Bed $\times$ season & 1 & 12 & 5.86 & 0.0323 \\
Irrigation $\times$ bed $\times$ season & 2 & 32 & 3.37 & 0.0468 \\
Year & 1 & 2 & 13.94 & 0.0648 \\
Irrigation $\times$ year & 2 & 32 & 11.63 & 0.0002 \\
Bed $\times$ year & 1 & 12 & 9.14 & 0.0106 \\
Irrigation $\times$ bed $\times$ year & 2 & 32 & 1.26 & 0.2982 \\
Season $\times$ year & 1 & 12 & 19.55 & 0.0008 \\
Irrigation $\times$ season $\times$ year & 2 & 32 & 0.44 & 0.6507 \\
Bed $\times$ season $\times$ year & 1 & 12 & 0.40 & 0.5375 \\
Irrigation $\times$ bed $\times$ season $\times$ year & 2 & 32 & 0.09 & 0.9119 \\
\hline
\end{tabular}
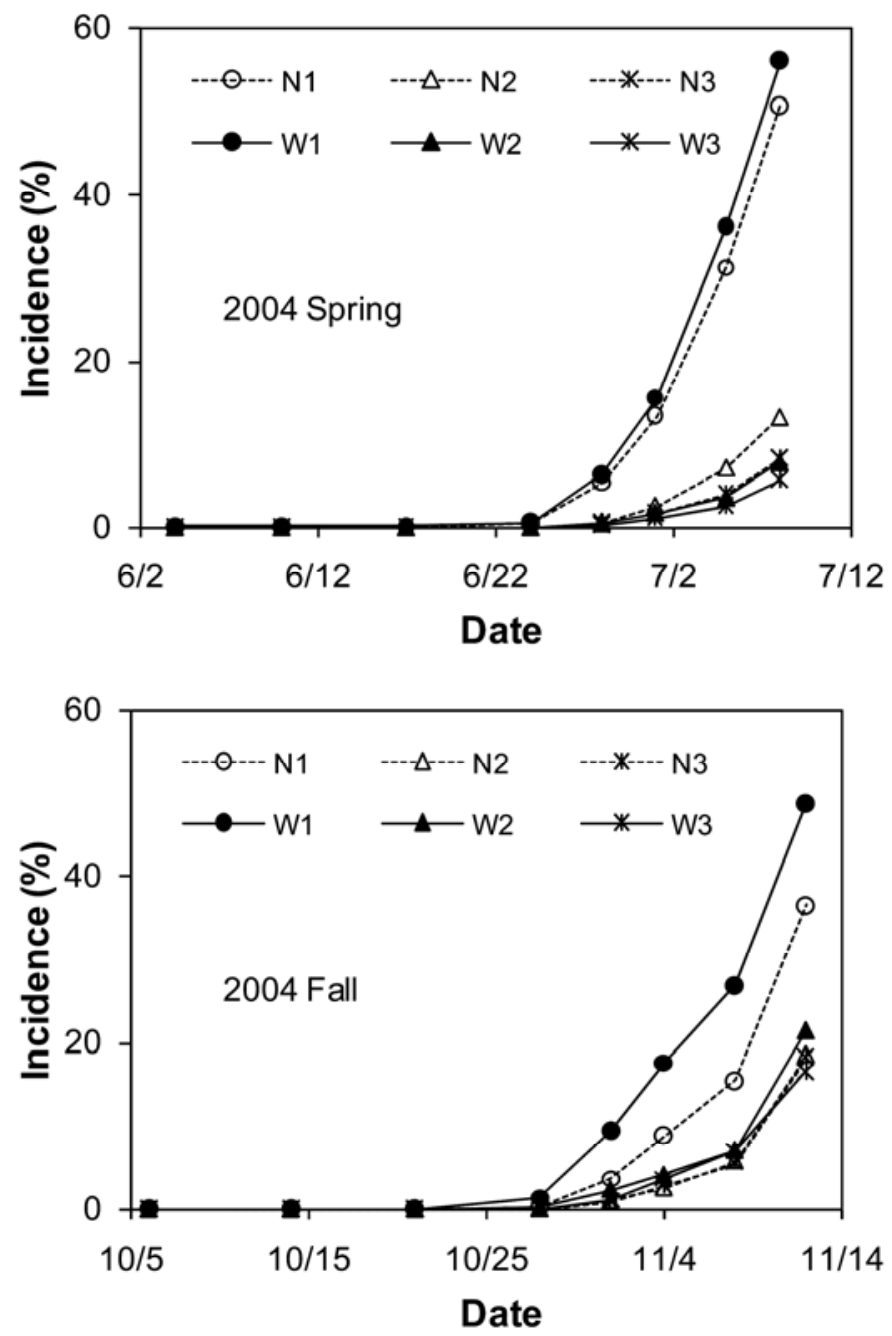

Fig. 2. Progress curves of lettuce drop caused by Sclerotinia sclerotiorum during spring and fall 2004. N1, N2, and N3 denote plots of 1-m-wide beds while W1, W2, and W3 denote 2-m-wide beds with twice-weekly, weekly, and biweekly irrigation frequencies, respectively. 
5). The effects of irrigation frequency and interaction of irrigation frequency-bed width as well as significant accumulation over cropping seasons were significant but the effects of bed width was not significant (Table 5). The effect of bed width was only significant for the twice-weekly irrigation frequency, when different irrigation frequencies were analyzed separately (data not shown).

The field surveys in 2000, 2005, and 2006 indicated that, in the southern part of the Salinas Valley, the percent fields infested with S. sclerotiorum increased from 2000 to 2006 although the difference was not statistically significant between years and there was no trend in the northern part of the Valley (Table 6).

Release and dispersal of ascospores. Fully developed apothecia of $S$. sclerotiorum released ascospores intermittently throughout the day (Fig. 6A). A major release peak occurred between 10:00 a.m. and 2:00 p.m., and a major dip was observed from late afternoon to early evening (3 to 9:00 p.m.) (Fig. 6A). A sine function, $y=62.835+53.682 \times \sin \left\{\left[(t / 24)^{1.591}-0.0306\right] \times 2 \pi\right\}$, fitted the temporal pattern of ascospore release and accounted for $71.4 \%$ of the total observed variation $\left(R^{2}=0.714, n=12\right)$. The fitted sine curve was nonsymmetrical; the number of released ascospores increased gradually before peaking at noon, then declined rapidly in the afternoon (Fig. 6A). The lowest spore release was observed at $\approx 7: 00$ p.m. (Fig. 6A). Ascospore release in S. sclerotiorum is an active mechanism and spore clouds form whenever the apothecia encounter changes in the atmospheric pressure $(7,11)$. The number of ascospores disseminated from the inoculum source declined rapidly with distance from the source (Fig. 6B). This decline was more rapid in the upwind direction than in the downwind direction (Fig. 6B). As the distance to the inoculum source increased beyond $3 \mathrm{~m}$, the number of ascospores decreased to a very low level, although a few ascospores were sampled at $11 \mathrm{~m}$ from the inoculum source (Fig. 6B).

\section{DISCUSSION}

Bed width and irrigation frequency significantly affected lettuce drop caused by $S$. minor, the dominant species in the Salinas Valley. Lettuce drop incidence in 2-m-wide beds with twiceweekly drip irrigation was significantly higher than at other irrigation frequencies. This synergistic interaction between wider bed width and the commercially practiced irrigation frequency led to slower drainage in the center of the beds and, consequently, higher soil moisture, contributing to higher disease incidence. The results from this study on $S$. minor are consistent with the previously established (10) relationship between higher soil moisture and increased germination of $S$. minor sclerotia. Conversely, despite the presence of sclerotia, low soil moisture resulted in sig-

TABLE 2. Type III tests of fixed effects from the mixed model analysis of the final lettuce drop incidence caused by Sclerotinia sclerotiorum

\begin{tabular}{lcccr}
\hline & Num & Den & & \\
Effect & DF & DF & $F$ value & $P>F$ \\
\hline Irrigation & 2 & 40 & 408.16 & $<0.0001$ \\
Bed & 1 & 40 & 5.43 & 0.0249 \\
Irrigation $\times$ bed & 2 & 40 & 15.54 & $<0.0001$ \\
Season & 1 & 6 & 43.3 & 0.0006 \\
Irrigation $\times$ season & 2 & 40 & 92.55 & $<0.0001$ \\
Bed $\times$ season & 1 & 40 & 0.51 & 0.4783 \\
Irrigation $\times$ bed $\times$ season & 2 & 40 & 1.13 & 0.3341 \\
Year & 1 & 6 & 78.33 & 0.0001 \\
Irrigation $\times$ year & 2 & 40 & 18.8 & $<0.0001$ \\
Bed $\times$ year & 1 & 40 & 2.37 & 0.1317 \\
Irrigation $\times$ bed $\times$ year & 2 & 40 & 0.44 & 0.6468 \\
Season $\times$ year & 1 & 6 & 107.68 & $<0.0001$ \\
Irrigation $\times$ season $\times$ year & 2 & 40 & 2.65 & 0.0827 \\
Bed $\times$ season $\times$ year & 1 & 40 & 8.39 & 0.0061 \\
Irrigation $\times$ bed $\times$ season $\times$ year & 2 & 40 & 0.41 & 0.6639 \\
\hline
\end{tabular}

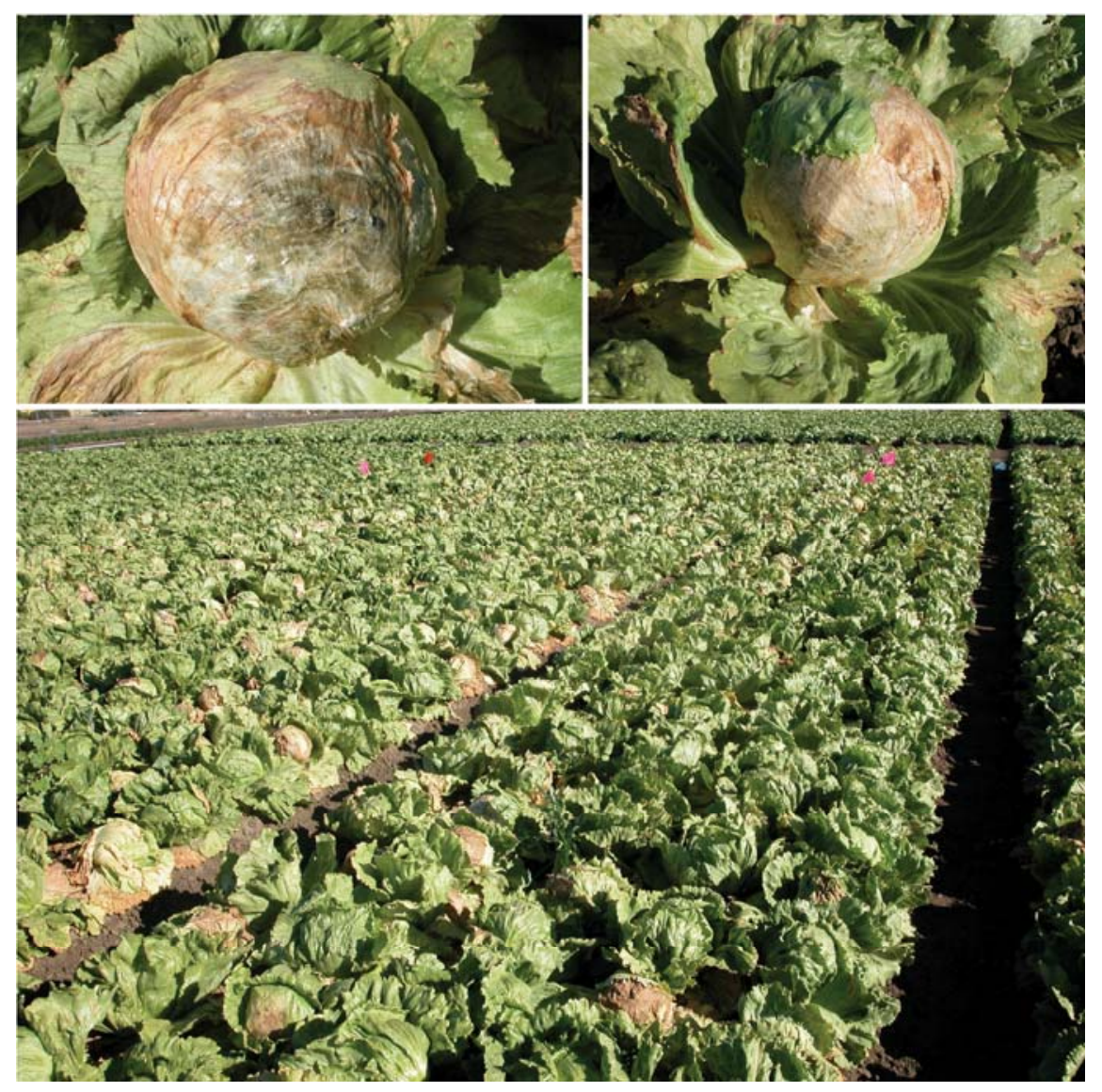

Fig. 3. Lettuce drop caused by airborne ascospores of Sclerotinia sclerotiorum. 
nificantly lower lettuce drop caused by $S$. minor $(4,27)$. Furthermore, higher lettuce drop incidence on 2-m-wide beds than on 1-m-wide beds may also be related to the increased canopy density, which can reduce evaporation and conserve soil moisture near the soil surface, which is optimal for eruptive germination of sclerotia and infection of lettuce plants. Similar effects of canopy density are well documented on Sclerotinia blight of peanut caused by $S$. minor, in which canopy pruning reduced disease incidence $(3,6,8)$.

Although the results on $S$. minor from the bed width-irrigation frequency interaction were predictable, the newly adopted bed configuration had unexpected consequences for lettuce drop

TABLE 3. Total amount of water received by plots under the different irrigation treatments regardless of the bed configuration in experiments with Sclerotinia minor and S. sclerotiorum

\begin{tabular}{lccc}
\hline & \multicolumn{3}{c}{ Total water received from irrigation $(\mathrm{cm})^{\mathrm{a}}$} \\
\cline { 2 - 4 } Cropping season & Irrigation 1 & Irrigation 2 & Irrigation 3 $^{\text {Srion }}$ \\
\hline S. sclerotiorum & & & \\
Spring 2004 & 19.9 & 7.9 & 6.2 \\
Fall 2004 & 9.6 & 5.0 & 3.4 \\
Spring 2005 & 17.0 & 9.1 & 5.2 \\
Fall 2005 & 12.3 & 5.7 & 3.3 \\
S. minor & & & \\
Spring 2004 & 23.0 & 12.5 & 7.1 \\
Fall 2004 & 11.0 & 6.7 & 4.0 \\
Spring 2005 & 20.1 & 10.9 & 6.3 \\
Fall 2005 & 21.1 & 10.8 & 4.9 \\
\hline
\end{tabular}

a Irrigation 1, 2, and 3 were drip irrigation treatments provided twice-weekly, weekly, and biweekly, respectively.

b Irrigation was skipped from 19 to 29 October 2004 because of rain.

caused by $S$. sclerotiorum in the Salinas Valley. Historically, infections caused by the mycelial germination of $S$. sclerotiorum have accounted for a few random plants in commercial fields and have not been considered a significant problem by the growers. However, as demonstrated in this study, the combination of 2-mwide beds and twice-weekly drip irrigation altered the condition, increased the production of apothecia relative to other treatments, and caused significantly high aerial infection by ascospores. Carpogenic germination of sclerotia of $S$. sclerotiorum requires a prolonged period ( $\geq 35$ days) of soil moisture at field capacity (31). Twengstrom et al. (28) also found that apothecia production required 25 to 30 days of continuous soil moisture and was

TABLE 4. Type III tests of fixed effects from the mixed model analysis of the number of apothecia produced by Sclerotinia sclerotiorum in $1 \mathrm{~m}^{2}$

\begin{tabular}{lccrr}
\hline & Num & Den & & \\
Effect & DF & DF & $F$ value & $P>F$ \\
\hline Irrigation & 2 & 44 & 151.35 & $<0.0001$ \\
Bed & 1 & 44 & 8.75 & 0.0050 \\
Irrigation $\times$ bed & 2 & 44 & 10.85 & 0.0001 \\
Season & 1 & 44 & 6.74 & 0.0128 \\
Irrigation $\times$ season & 2 & 44 & 0.70 & 0.5000 \\
Bed $\times$ season & 1 & 44 & 1.97 & 0.1672 \\
Irrigation $\times$ bed $\times$ season & 2 & 44 & 3.19 & 0.0508 \\
Year & 1 & 44 & 20.82 & 0.0103 \\
Irrigation $\times$ year & 2 & 44 & 16.03 & $<0.0001$ \\
Bed $\times$ year & 1 & 44 & 0.01 & 0.9184 \\
Irrigation $\times$ bed $\times$ year & 2 & 44 & 0.08 & 0.9262 \\
Season $\times$ year & 1 & 44 & 0.98 & 0.3279 \\
Irrigation $\times$ season $\times$ year & 2 & 44 & 0.15 & 0.8646 \\
Bed $\times$ season $\times$ year & 1 & 44 & 0.19 & 0.6621 \\
Irrigation $\times$ bed $\times$ season $\times$ year & 2 & 44 & 0.35 & 0.7050 \\
\hline
\end{tabular}
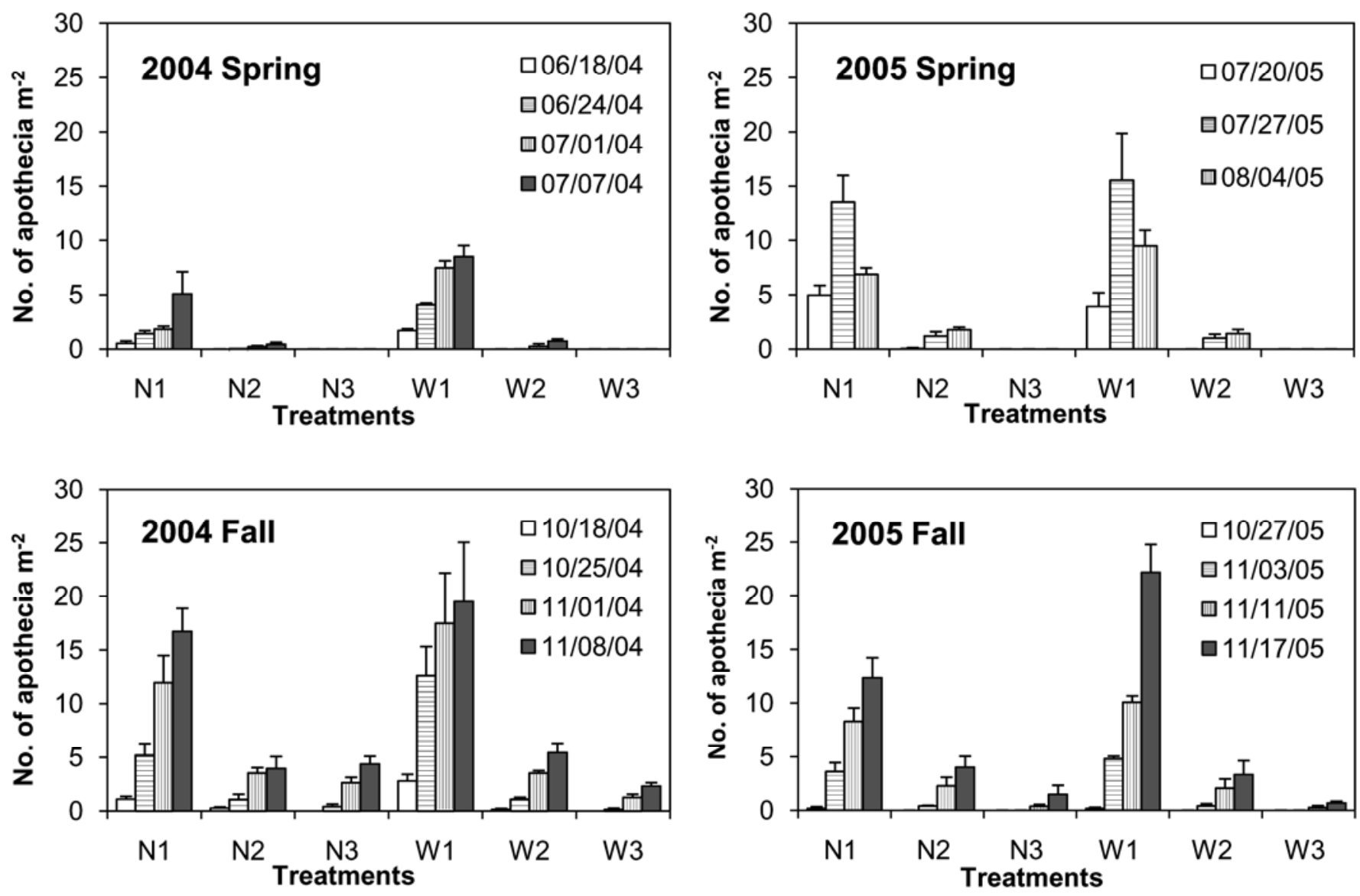

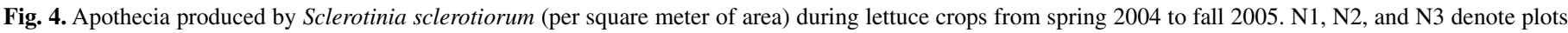

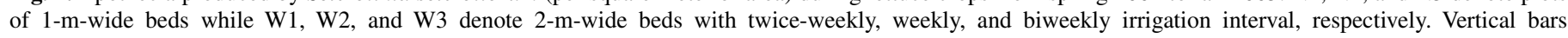
represented standard errors of the means. 
strongly influenced by the irrigation frequency. A 10- or 20-day dry period during this threshold 35-day period would completely arrest carpogenic germination of $S$. sclerotiorum, and new apothecia would develop after an interval of 35 days following rewetting, similar to the initial carpogenic germination regardless of when the dry period was imposed (31). The requirements of the sclerotia from $S$. sclerotiorum for the production of apothecia have been verified in a number of other crops. For example, lateral clipping of the canopy and removal of the debris reduced apothecia production and disease incidence of Sclerotinia rot in carrot (15), and disease severity and pod rot of white mold on snap bean declined linearly as between-row widths increased from 19 to $150 \mathrm{~cm}$. (19). The results from the current study demonstrated that twice-weekly irrigation together with 2-m-wide bed configuration can provide the continuous soil moisture required for carpogenic germination by $S$. sclerotiorum and that, when soil moisture conditions for the production of apothecia are satisfied, infection of lettuce by ascospores of $S$. sclerotiorum in both spring and fall seasons inevitably will ensue. In a previous study, we had demonstrated that the California populations of $S$.

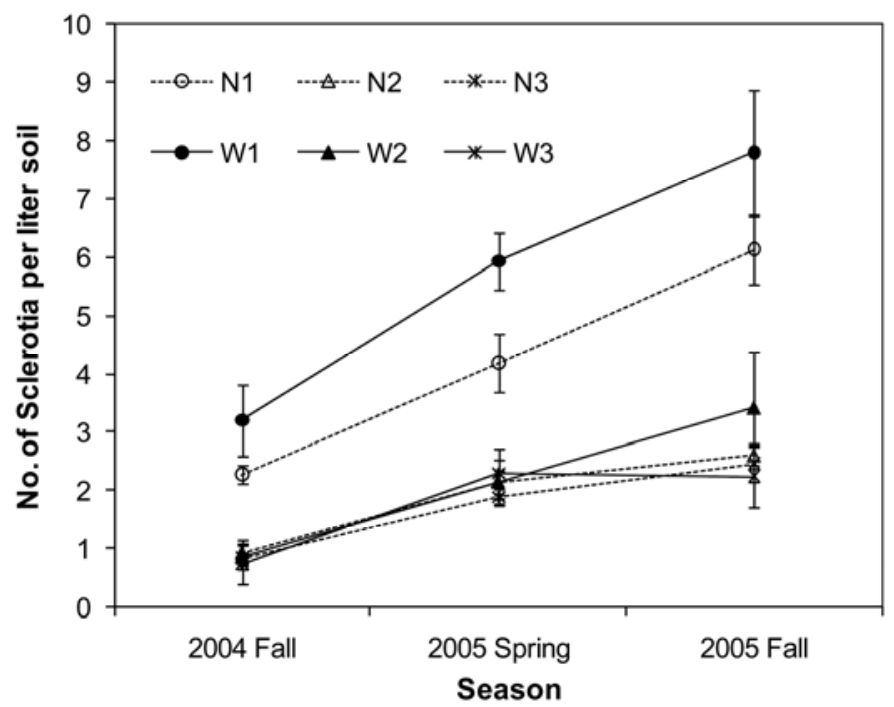

Fig. 5. Density of Sclerotinia sclerotiorum sclerotia in the topsoil (0 to $5 \mathrm{~cm})$ during lettuce crops. N1, N2, and N3 denote plots of 1-m-wide beds while W1,W2, and W3 denote 2-m-wide beds with twice-weekly, weekly, and biweekly irrigation interval, respectively. Vertical bars represented standard errors of the means.

TABLE 5. Results from the mixed-model analysis of the effects of bed width and irrigation regime on sclerotia density of Sclerotinia sclerotiorum in soil

\begin{tabular}{lccrr}
\hline Effect & Num DF & Den DF & $F$ value & \multicolumn{1}{c}{$P>F$} \\
\hline Irrigation & 2 & 24 & 100.02 & $<0.0001$ \\
Bed & 1 & 12 & 4.17 & 0.0637 \\
Irrigation $\times$ bed & 2 & 24 & 4.68 & 0.0192 \\
Crop & 2 & 12 & 29.90 & $<0.0001$ \\
Irrigation $\times$ crop & 4 & 24 & 5.41 & 0.0030 \\
Bed $\times$ crop & 2 & 12 & 0.33 & 0.7274 \\
Irrigation $\times$ bed $\times$ crop & 4 & 24 & 0.44 & 0.7790 \\
\hline
\end{tabular}

sclerotiorum do not require preconditioning (prolonged freezing to trigger apothecial production by sclerotia) of sclerotia to germinate carpogenically (31). Thus, the exposure of sclerotia to freezing temperatures for prolonged periods does not naturally happen in coastal California and is also not a requirement for the California populations.

Under subsurface drip irrigation, sclerotia of $S$. minor accumulate stably year over year but, under a furrow-irrigation system, even though the number of sclerotia increase significantly within a crop season, the increases were offset by the decline between seasons and, therefore, there was no consistent trend over years (29). In this study, the sclerotium density of S. sclerotiorum in the soil accumulated steadily over four cropping seasons in plots with twice-weekly surface drip irrigation and this accumulation was even more rapid in the $2-\mathrm{m}$ bed plots.

In the study with laboratory-produced apothecia buried in microplots, apothecia released ascospores during the day and

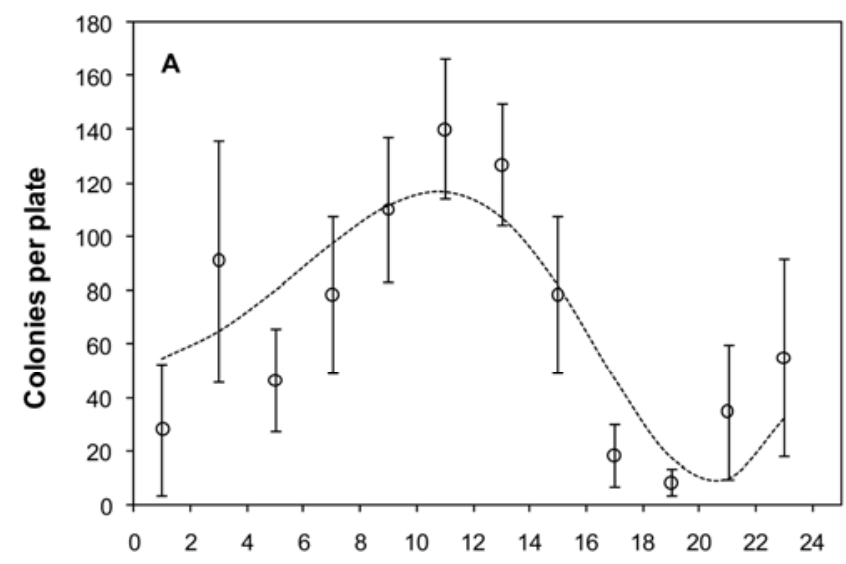

Time of the day (Pacific Standard Time)

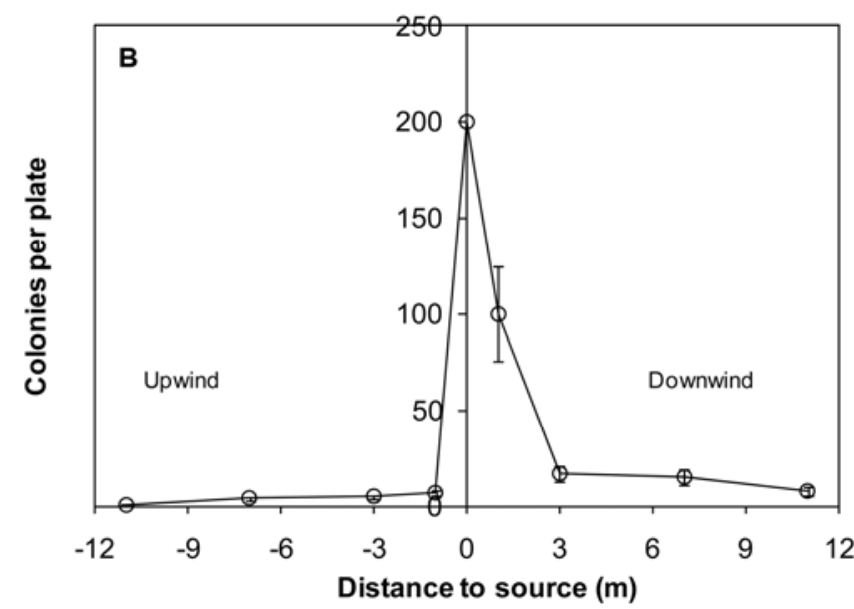

Fig. 6. A, Release of Sclerotinia sclerotiorum ascospores over different times of the day (hours in Pacific Standard Time) and $\mathbf{B}$, ascospore dispersal along upwind and downwind directions.

TABLE 6. Percentage of lettuce fields in the Salinas Valley with infections caused by Sclerotinia sclerotiorum during field surveys conducted in spring 2000, 2005, and 2006

\begin{tabular}{|c|c|c|c|}
\hline Parameters & 2000 & 2005 & 2006 \\
\hline South (latitude <36.41) (\%) & 37 & 40 & 46 \\
\hline North (latitude $\geq 36.41)(\%)$ & 18 & 21 & 17 \\
\hline Survey date & 15 April-17 May & 18-21 April & 4-7 May \\
\hline No. of fields with 2 -m-wide beds (south/north) & $\mathrm{N} / \mathrm{N}^{\mathrm{a}}$ & $5 / 7$ & $7 / 7$ \\
\hline
\end{tabular}

${ }^{a}$ Bed configuration was not recorded during the survey conducted in 2000. 
night, with a peak consistently observed at $\approx 10: 00$ a.m. to $12: 00$ p.m. This is consistent with the result of McCartney and Lacey (16), who found that the release of ascospores occurred predominantly during the day at approximately noon. The ascospores of $S$. sclerotiorum were detected over a distance of $11 \mathrm{~m}$ from the inoculum source along the downwind direction but the concentration was no more than $5 \%$ of that at the inoculum source, which was not accurately quantified due to the limitation of colony counting on plates. This observation is comparable with the previous report, in which ascospore concentration at $10 \mathrm{~m}$ from the source was $\approx 1 \%$ of that at the inoculum source (5), although both the source of inoculum and the wind speed were different in the two studies. The steep dispersal gradient suggests that aerial infections in any lettuce field are predominately caused by ascospores produced within the same field. Although longdistance transport of ascospores is important in spread or exploration into new fields, this role is not important in the southern Salinas Valley, where $46 \%$ of lettuce fields had been infested with S. sclerotiorum by 2006 . Therefore, to mitigate the threat of this pathogen to lettuce production, management strategy should be focused on reducing the carpogenic germination by the pathogen during cropping seasons, such as avoiding cultivation of lettuce during rainy early spring seasons or avoiding frequent irrigation and dense canopy during spring and summer cropping seasons when rainfall is rare in central coastal California.

The significant difference in the incidence of lettuce drop caused by $S$. sclerotiorum also confirmed that the interference among plots that were separated by $4 \mathrm{~m}$ (four 1-m, two 2-m, or two 1-m plus one 2-m beds) was limited; therefore, the contribution of inoculum sources from nearby plots was limited. Although differences among treatments in fall 2004 were lower than in spring 2004, this might be attributed mainly to the rainfall from 16 to 29 October 2004, which resulted in a much higher number of apothecia in plots with less frequent irrigation during fall 2004 than in spring 2004. It might be a coincidence that the first aerial infection of lettuce together with apothecia in the Salinas Valley was first observed in the fall (B. M. Wu and K. V. Subbarao, unpublished data). It will be interesting to conduct more surveys to see if early rain in the fall is associated with increased incidence of lettuce drop caused by S. sclerotiorum.

One interesting finding of this study was that the final disease incidence caused by $S$. sclerotiorum was significantly lower in fall 2005 than in other cropping seasons. A possible reason for this could be the late planting during this season. Late planting resulted in delayed canopy closing and compressed the time between canopy closing and harvest owing to the lettuce-free period requiring that no lettuce tissue be present in commercial fields by 7 December (25). Because the topsoil could only remain continuously moist after canopy closure, and it takes $\approx 35$ days for sclerotia to produce apothecia, the short time between canopy closing and harvest was insufficient for ascospores to infect the lettuce crop and for the disease to develop in the field. This finding implies that early harvest may be used as a practice to reduce the yield losses caused by airborne infections of $S$. sclerotiorum when disease pressure is high.

For many decades, S. minor has been the only important Sclerotinia sp. to cause lettuce drop in the Salinas Valley of California, the most important lettuce production area in the world. So far, S. sclerotiorum has never been a serious threat to lettuce production in this area. However, in three of the four cropping seasons during this study, drop incidence from aerial infections by $S$. sclerotiorum reached as high as $>50 \%$ in plots with twiceweekly drip irrigation and 2-m bed width. Even though the initial inoculum levels in commercial fields may be much lower than those established in our experimental plots during this study, given the steady season after season accumulation of sclerotia in the soil, it is not impossible for the density of sclerotia in the soil to reach the threshold to cause significant yield losses. These increases in the soilborne sclerotia of S. sclerotiorum coupled with the increased adaptation of the $2-\mathrm{m}$ bed configuration to produce greater lettuce biomass and its consequent optimal conditions for the production of apothecia by this fungus may lead to the establishment of the hitherto unseen but highly destructive airborne ascospore phase. Consequently, S. sclerotiorum could become a serious threat to lettuce production in the Salinas Valley.

In conclusion, examples of studies on changes in crop production practices dictated by consumer preferences and their potential impact on plant diseases are rare in plant pathology. As this study demonstrates, such changes, however sound economically in the short term, can potentially have significant effects on crop diseases over the longer term. In the process, they also have the potential to alter the long-established species balance in a given ecological niche that, in turn, could pose significant longterm threats to crop production.

\section{LITERATURE CITED}

1. Abawi, G. S., and Grogan, R. G. 1975. Source of primary inoculum and effects of temperature and moisture on infection of beans by Whetzelinia sclerotiorum. Phytopathology 65:300-309.

2. Abawi, G. S., and Grogan, R. G. 1979. Epidemiology of disease caused by Sclerotinia species. Phytopathology 69:899-904.

3. Bailey, J. E., and Brune, P. D. 1997. Effect of crop pruning on Sclerotinia blight of peanut. Plant Dis. 81:990-995.

4. Bell, A. A., Liu L., Reidy, B., Davis, R. M., and Subbarao, K. V. 1998. Mechanisms of subsurface drip irrigation-mediated suppression of lettuce drop caused by Sclerotinia minor. Phytopathology 88:252-259.

5. Bourdot, G. W., Hurrell, G. A., Saville, D. J., and De Jong, M. D. 2001. Risk analysis of Sclerotinia sclerotiorum for biological control of Cirsium arvense in pasture: Ascospore dispersal. Biocontrol Sci. Technol. 11:119139.

6. Butzler, T. M., Bailey, J., and Beute, M. K. 1998. Integrated management of Sclerotinia blight in peanut: Utilizing canopy morphology, mechanical pruning, and fungicide timing. Plant Dis. 82:1312-1318.

7. Dickson, L. F., and Fisher, W. R. 1923. A method of photographing spore dispersal from apothecia. Phytopathology 13:30-32.

8. Dow, R. L., Powell, N. L., and Porter, D. M. 1988. Effects of modification of the plant canopy environment on Sclerotinia blight of peanut. Peanut Sci. 15:1-5.

9. Grube, R. G., and Ryder, E. J. 2004. Identification of lettuce (Lactuca sativa L.) germplasm with genetic resistance to drop caused by Sclerotinia minor. J. Am. Soc. Hortic. Sci. 129:70-76.

10. Hao, J. J., Subbarao, K. V., and Duniway, J. M. 2003. Germination of Sclerotinia minor and $S$. sclerotiorum sclerotia under various soil moisture and temperature combinations. Phytopathology 93:443-450.

11. Harthill, W. F. T., and Underhill, A. P. 1976. Puffing in Sclerotinia sclerotiorum and S. minor. N. Z. J. Bot. 14:355-358.

12. Hayes, R. J., Wu, B. M., Pryor, B. M., Chitrampalam, P., and Subbarao, K. V. 2010. Assessment of resistance in lettuce (Lactuca sativa L.) to mycelial and ascospore infection by Sclerotinia minor Jagger and $S$. sclerotiorum (Lib.) de Bary. Hortscience 45:333-341.

13. Hubbard, J. C., Subbarao, K. V., and Koike, S. T. 1997. Development and significance of dicarboximide resistance in Sclerotinia minor isolates from commercial lettuce fields in California. Plant Dis. 81:148153.

14. Klose, S., Wu, B. M., Ajwa, H. A., Koike, S. T., and Subbarao, K. V. 2010. Reduced efficacy of rovral and botran to control Sclerotinia minor in lettuce production in the Salinas Valley may be related to accelerated fungicide degradation in soil. Crop Prot. 29:751-756.

15. Kora, C., McDonald, M. R., and Boland, G. J. 2005. Lateral clipping of canopy influences the microclimate and development of apothecia of Sclerotinia sclerotiorum in carrots. Plant Dis. 89:549-557.

16. McCartney, H. A., and Lacey, M. E. 1991. The relationship between the release of ascospores of Sclerotinia sclerotiorum, infection and disease in sunflower plots in the United Kingdom. Grana 30:486-492.

17. Newton, C. H., and Sequeira, L., 1972. Ascospores as the primary infective propagule of Sclerotinia sclerotiorum in Wisconsin. Plant Dis. Rep. 56:798-802.

18. Patterson, C. L., and Grogan, R. G. 1985. Differences in epidemiology and control of lettuce drop caused by Sclerotinia minor and Sclerotinia sclerotiorum. Plant Dis. 69:766-770.

19. Peachey, E. D., Ludy, R. L., Powelson, M. L., and McGrath, D. M. 2006. Modification of plant arrangement suppresses white mold of snap beans. 
Hortscience 41:1298-1302.

20. Purdy, L. H. 1979. Sclerotinia sclerotiorum: history, diseases and symptomatology, host range, geographic distribution, and impact. Phytopathology 69:875-880.

21. Ryder, E. J. 1999. Lettuce, Endive, and Chicory. Crop Production in Horticulture Series, Vol. 7. CAB International, Cambridge.

22. Schwartz, H. F., and Steadman, J. R. 1978. Factors affecting sclerotium populations of, and apothecium production by, Sclerotinia sclerotiorum. Phytopathology 68:383-388.

23. Steadman J. R., Marcinkowska, J., and Rutledge, S. 1994. A semiselective medium for isolation of Sclerotinia sclerotiorum. Can. J. Plant Pathol. 16:68-70.

24. Subbarao, K. V. 1997. Lettuce drop. Pages 19-21 in: Compendium of Lettuce Diseases. R. M. Davis, K. V. Subbarao, R. N. Raid, and E. A. Kurtz, eds. American Phytopathological Society, St. Paul, MN.

25. Subbarao, K. V. 1998. Progress toward integrated management of lettuce drop. Plant Dis. 82:1068-1078.

26. Subbarao, K. V., Dacuyan, S., Koike, S. T., and Jackson, L. E. 1994. Evaluation of three quantitative assays for Sclerotinia minor. Phyto- pathology 84:1471-1475.

27. Subbarao, K. V., Hubbard, J. C., and Schulbach, K. F. 1997. Comparison of lettuce diseases and yield under subsurface drip and furrow irrigation. Phytopathology 87:877-883.

28. Twengstrom, E., Kopmans, E., Sigvald, R., and Svensson, C. 1998. Influence of different irrigation regimes on carpogenic germination of sclerotia of Sclerotinia sclerotiorum. J. Phytopathol. 146:487-493.

29. Wu, B. M., and Subbarao, K. V. 2003. Effects of irrigation and tillage on the dynamics of Sclerotinia minor sclerotia and lettuce drop incidence. Phytopathology 93:1572-1580.

30. Wu, B. M., and Subbarao, K. V. 2006. Analyses of lettuce drop incidence and population structure of Sclerotinia sclerotiorum and S. minor. Phytopathology 96:1322-1329.

31. Wu, B. M., and Subbarao, K. V. 2008. Effects of soil temperature, moisture and burial depths on carpogenic germination of Sclerotinia sclerotiorum and S. minor. Phytopathology 98:1144-1152.

32. Wu, B. M., Subbarao, K. V., and Liu, Y. B. 2008. Comparative survival of sclerotia of Sclerotinia minor and S. sclerotiorum. Phytopathology 98:659-665. 